\title{
Targeted temperature management in emergency medicine: current perspectives
}

\author{
This article was published in the following Dove Press journal: \\ Open Access Emergency Medicine \\ 28 September 2015 \\ Number of times this article has been viewed
}

\author{
Benton R Hunter ${ }^{\prime}$ \\ Timothy J Ellender ${ }^{1,2}$ \\ 'Department of Emergency Medicine, \\ 2Department of Critical Care Medicine, \\ Indiana University School of Medicine, \\ Indiana University, Indianapolis, IN, USA
}

Correspondence: Benton R Hunter Department of Emergency Medicine, Indiana University School of Medicine, Indiana University, 2806 East High Grove Circle, Zionsville, IN 46077, USA

$\mathrm{Tel}+\mathrm{I} 3174132318$

Email brhunter@iupui.edu

\begin{abstract}
Landmark trials in 2002 showed that therapeutic hypothermia (TH) after out-ofhospital cardiac arrest due to ventricular tachycardia or ventricular fibrillation resulted in improved likelihood of good neurologic recovery compared to standard care without TH. Since that time, $\mathrm{TH}$ has been frequently instituted in a wide range of cardiac arrest patients regardless of initial heart rhythm. Recent evidence has evaluated how, when, and to what degree $\mathrm{TH}$ should be instituted in cardiac arrest victims. We outline early evidence, as well as recent trials, regarding the use of TH or targeted temperature management in these patients. We also provide evidence-based suggestions for the institution of targeted temperature management/ $\mathrm{TH}$ in a variety of emergency medicine settings.
\end{abstract}

Keywords: therapeutic hypothermia, cardiac arrest, heart arrest

\section{Introduction}

Cardiac arrest is common, occurring in more than 320,000 nonhospitalized people yearly in the USA alone. ${ }^{1}$ Of those treated by emergency medical services personnel, approximately $23 \%$ present with a shockable initial heart rhythm (ventricular tachycardia or ventricular fibrillation [VF]). ${ }^{1}$ Despite ongoing efforts to improve resuscitative and postresuscitative care, cardiac arrest still carries a dismal prognosis, with survival to hospital discharge occurring in $7 \%-11 \%$ of patients with out-of-hospital cardiac arrest $(\mathrm{OHCA})^{1,2}$ and $25 \%$ of patients who arrest in hospital. ${ }^{1}$ Historically, once return of spontaneous circulation (ROSC) is achieved, there is little evidence to support any particular therapy or intervention. In 2002, two landmark studies ${ }^{3,4}$ reported that cooling the bodies of postarrest patients who had an initially shockable heart rhythm to $32^{\circ} \mathrm{C}-34^{\circ} \mathrm{C}$ for a period of time after ROSC resulted in a greater likelihood of neurologically intact survival. This therapeutic hypothermia (TH) has since become standard care for patients with ROSC after cardiac arrest. Despite a lack of high-level evidence in cardiac arrest patients with nonshockable initial rhythms or in-hospital arrest, TH is now commonly applied to any patient with ROSC after cardiac arrest, whether in hospital or OHCA, and any presenting rhythm. ${ }^{5-7}$

Recently, two large randomized trials ${ }^{8,9}$ introduced considerable controversy to the discussion about how, when, and to what degree we should be instituting temperature control in postarrest patients. The objective of this review is to give an overview of the evidence surrounding TH in patients with ROSC after cardiac arrest, and provide evidence-based suggestions for temperature management of cardiac arrest victims in a variety of emergency-medicine settings. When possible, we focus on evidence from randomized trials. We try to address specifically when, how, and to what temperature 
we should be managing the temperature of postarrest patients. Lastly, we present a structure for instituting temperature control and outline some pearls and pitfalls in doing so. We use the term "targeted temperature management" (TTM) to refer to strict temperature control at any temperature. TH will be used to refer to temperature control targeting body temperatures of $32^{\circ} \mathrm{C}-34^{\circ} \mathrm{C}$.

\section{Background and pathophysiology}

TTM is a form of treatment aimed at achieving and maintaining a specific core body temperature for a duration of time to improve outcomes. ${ }^{10}$ This is done in an attempt to reduce the risk of tissue injury from the lack of blood flow that can be seen as a result of cardiac arrest. TTM is thought to limit brain injury by decreasing cellular metabolism and the brain's oxygen demand by reducing the production of excitatory neurotransmitters like glutamate, minimizing the disruption of ion homeostasis, and by reducing free radicals that might further injure at-risk neurons. ${ }^{11-13}$ Most centers now either actively cool or control temperature by using $\mathrm{TH}$ or temperature-management protocol (example in Figure 1) for 24 hours to a goal cooling temperature of $32^{\circ} \mathrm{C}-34^{\circ} \mathrm{C}$

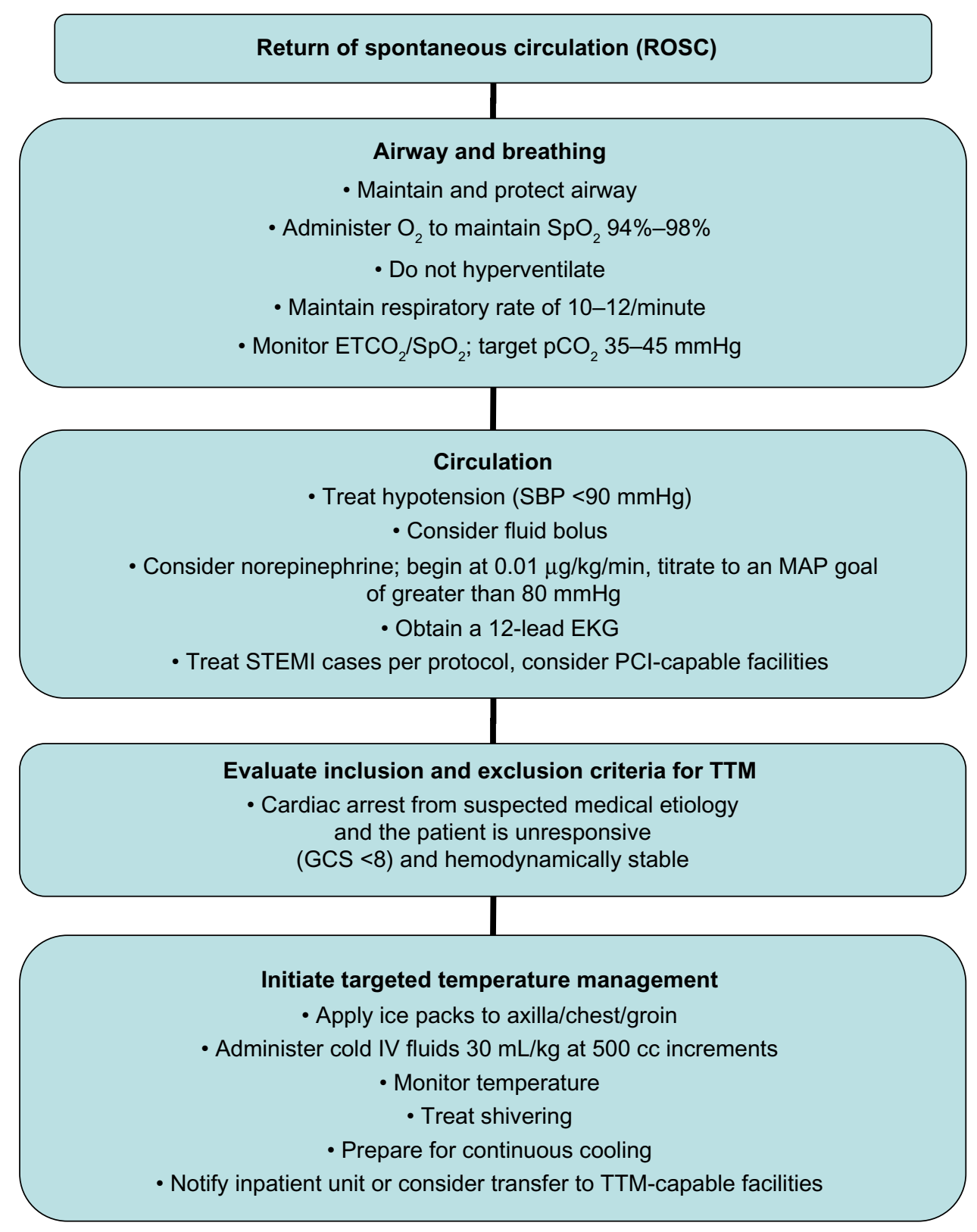

Figure I Targeted temperature management (TTM).

Abbreviations: $\mathrm{SpO}_{2}$, peripheral capillary oxygen saturation; $\mathrm{ETCO}_{2}$, end-tidal carbon dioxide; $\mathrm{PCO}$, partial pressure of carbon dioxide; SBP, systolic blood pressure; MAP, mean arterial pressure; EKG, electrocardiogram; STEMI, ST-elevation myocardial infarction; PCl, percutaneous coronary intervention; GCS, Glasgow Coma Score; IV, intravenous. 
or maintain normothermia at $36^{\circ} \mathrm{C} \cdot{ }^{14-16}$ Standard protocols aim for initiating temperature control within the 1 st hours of collapse (0-6 hours) to achieve the target temperature as quickly as possible (within 8 hours of cooling initiation). ${ }^{14,16,17}$ Rewarming is typically begun 24 hours after the initiation of cooling for patients cooled to a $32^{\circ} \mathrm{C}-34^{\circ} \mathrm{C}$ target, and is done slowly $\left(0.1^{\circ} \mathrm{C}-0.5^{\circ} \mathrm{C}\right.$ per hour $)$ until $36^{\circ} \mathrm{C}$ is reached. In some centers, temperature management is maintained at $36^{\circ} \mathrm{C}$ for the next 48 hours independently of initial target temperature. Likewise, centers that use $36^{\circ} \mathrm{C}$ as a temperature-management target typically control body temperature at this target for 72 hours.

A basic understanding of some landmark trials in $\mathrm{TH}$ is necessary in order to try to answer some of the questions we address in this article. TH after cardiac arrest was brought to the forefront in 2002 by two trials published in the New England Journal of Medicine. Bernard et $\mathrm{al}^{3}$ enrolled 77 patients with ROSC after OHCA and an initial cardiac rhythm of VF in a quasi-randomized fashion. Patients assigned to TH had cold packs and ice packs applied to their head, neck, and torsos until they were $33^{\circ} \mathrm{C}$. This temperature was maintained for at least 12 hours. Patients were then rewarmed with heating blankets to normothermia by 24 hours after hospital admission. Twenty-one of 43 patients (49\%) assigned to hypothermia were released from the hospital with "good neurologic outcome". This end point was achieved in only nine of 34 patients (26\%) assigned to no temperature control, which was a statistically significant difference.

At the same time, a second trial was published by the Hypothermia After Cardiac Arrest (HACA) study group. ${ }^{4}$ This larger randomized trial similarly enrolled postarrest patients who had an initial rhythm that was shockable (ventricular tachycardia or VF). Of approximately 3,500 patients screened, the trial ultimately enrolled 275 patients. Those randomized to $\mathrm{TH}$ were cooled to a target of $32^{\circ} \mathrm{C}-34^{\circ} \mathrm{C}$ using cooling blankets that circulated cold air, with ice bags used additionally if necessary. This temperature was maintained for approximately 24 hours, followed by passive rewarming. This trial found that 75 of 136 patients (55\%) randomized to $\mathrm{TH}$ had a "favorable neurologic outcome" compared to 54 of 137 (39\%) of the normothermic patients. Again, this difference in outcomes was statistically significant.

The methods and duration of cooling in these trials were, as just outlined, heterogeneous, but the results were consistent and suggested a large increase in neurologically intact survival with TH employed by relatively simple methods.
While these two trials have formed the backbone of support

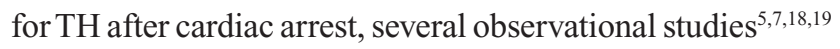
have been published since then, mostly reporting similar benefits associated with TH. In 2002, the International Liaison Committee on Resuscitation began recommending $\mathrm{TH}$ be instituted in all patients with ROSC after an initially shockable rhythm and considered in those with nonshockable rhythms. ${ }^{20}$ These guidelines have not changed significantly since then.

In 2013, Nielsen et al published a much larger randomized trial that compared controlled normothermia at $36^{\circ} \mathrm{C}$ to controlled hypothermia at $33^{\circ} \mathrm{C} .{ }^{9}$ This trial enrolled patients with any initial rhythm, and patients were cooled with more sophisticated equipment, which allowed more tightly controlled body temperatures. In this trial of over 950 patients, the two temperature targets were equivalent in terms of survival and neurologically intact recovery. Among the patients cooled to $33^{\circ} \mathrm{C}$, mortality was $50 \%$ at the end of the trial, and $54 \%$ had either died or had poor neurologic function at 180 days. Of the patients maintained at $36^{\circ} \mathrm{C}$, the corresponding numbers were $48 \%$ mortality and $52 \%$ with poor neurologic outcome or death. Results were similar for patients with shockable or nonshockable rhythms. There was no statistical difference in outcomes, and the authors concluded that $\mathrm{TH}$ at $33^{\circ} \mathrm{C}$ conferred no benefit over TTM at $36^{\circ} \mathrm{C}$.

At nearly the same time, Kim et al published a negative trial of prehospital $\mathrm{TH}^{8}{ }^{8}$ This trial randomized 1,369 patients with OHCA to either immediate cooling by prehospital providers with cold saline $\left(4^{\circ} \mathrm{C}\right)$ or standard prehospital management without cooling. By protocol, the patients who survived to hospital admission were to undergo $\mathrm{TH}$ in the hospital. Survival was $37.6 \%$ in patients cooled in the field versus $37.1 \%$ in controls. Good neurologic recovery was $32.7 \%$ in cooled patients versus $34.4 \%$ in controls. Results were similar for patients with initial shockable and nonshockable rhythms, though in-hospital TH was inconsistently applied to patients with nonshockable rhythms.

An understanding of these few trials is imperative for any informed discussion regarding the finer points of when and how to institute TTM after cardiac arrest. These trials are referenced throughout the rest of this review.

\section{What is the optimal temperature target?}

Prior to Nielsen et al's study, ${ }^{9}$ data from randomized trials were limited to demonstrating that $32^{\circ} \mathrm{C}-34^{\circ} \mathrm{C}$ for $12-24$ hours was superior to no temperature control. There was very limited evidence to guide further what exact temperature would be most beneficial. Further, this benefit was only proven in 
patients with shockable rhythms on presentation. Nielsen et al's study showed that strict temperature management to maintain normothermia at $36^{\circ} \mathrm{C}$ resulted in similar outcomes to hypothermia at $33^{\circ} \mathrm{C}$. The study included patients with any presenting rhythm. The authors postulated that fever avoidance was the key, as opposed to actual cooling to a hypothermic temperature. Nielsen et al did find that electrolyte abnormalities were slightly more common in patients cooled to $33^{\circ} \mathrm{C}$, which is of unclear clinical meaning. In a secondary analysis, the authors also found that vasopressor requirements were higher in the hypothermic group compared to patients maintained at normothermia. ${ }^{21}$ It thus may be that a target of $36^{\circ} \mathrm{C}$ is associated with moderately fewer side effects than a hypothermic protocol, but these small differences did not result in a difference in patient-important outcomes. There are no convincing data to suggest that one temperature target is superior to another.

A recent trial ${ }^{22}$ representing the first randomized trial of $\mathrm{TH}$ versus normothermia in children found that temperature management at a goal of $36.8^{\circ} \mathrm{C}$ was as effective as targeting $33^{\circ} \mathrm{C}$. Enrollees had their target temperature maintained for the first 48 hours, then were brought to a target of $36.8^{\circ} \mathrm{C}$ through a total of 120 hours of temperature control. The trial enrolled 260 patients with full outcome data, and found that survival with good neurologic recovery was $20 \%$ in the hypothermia group and $12 \%$ in the normothermia group $(P=0.14)$. Secondary outcomes were similarly distributed and not statistically different between the groups.

Given the results of these randomized studies and lack of meaningful benefit or harm associated with hypothermia versus controlled normothermia, either temperature goal seems reasonable. Practice patterns may eventually be decided by which temperature target is easier to maintain. If a simple and inexpensive method for maintaining temperature at $36^{\circ} \mathrm{C}$ is validated, decreasing costs compared to hypothermia, this might make a stronger argument for normothermia. It should be pointed out, however, that both of these trials comparing TTM at different temperatures ${ }^{9,22}$ used advanced temperature-control devices in all of the enrolled patients. While these devices have not proven superior to easy, inexpensive methods (ice packs and cold saline) for patients receiving $\mathrm{TH},{ }^{23}$ their efficacy compared to simple methods has not been studied in controlled normothermia.

\section{Special considerations for choosing a temperature target}

Adverse events and possible complications of hypothermia may include bleeding, dysrhythmias, electrolyte abnormalities, hyperglycemia, infection, and skin breakdown. ${ }^{11,12,24-26}$ Though fatal arrhythmia produced by hypothermia is seemingly rare, sinus tachycardia is commonly seen at the time of hypothermia induction, and when body temperature falls below $35.5^{\circ} \mathrm{C}$, a sinus bradycardia occurs. ${ }^{27,28}$ Typical electrocardiogram changes seen during hypothermia include an increase in the intervals between different waves ( $\mathrm{P}-\mathrm{R}, \mathrm{Q}-\mathrm{T})$, the widening of the wave of ventricular depolarization (QRS), and occasionally a prominent J-point deflection or Osborne wave. ${ }^{28}$ Serum electrolyte disturbances occur as a result of increased renal excretion of electrolytes, due to changes in circulating blood volume, cardiac preload, and impaired tubular function and as a result of intracellular shift during hypothermia. ${ }^{27,28}$ The most common electrolyte disturbances seen are magnesium deficiency and hypokalemia, though hypocalcemia, hyponatremia, and hypophosphatemia also occur with some frequency. ${ }^{28}$ Though many of these disturbances can be transient, preventing severe electrolyte imbalance caused by hypothermia should be the main target of electrolyte treatment. ${ }^{27,28}$ Infection, historically the most feared risk of prolonged $\mathrm{TH}$, might have no greater prevalence in this population than that of matched critically ill patients. ${ }^{24}$ Similarly, recent investigators found that hypothermia was associated with a small but not statistically significant trend toward increased bleeding, and found no associated increase in severe bleeding. ${ }^{26}$ Invasive lines, especially cooling catheters, can predispose resuscitated patients to inadvertent vascular puncture, bleeding, infection, and deep-vein thrombosis, so extreme care must be taken during placement and maintenance..$^{25,27}$

In summary, there is little evidence to suggest that meaningful complications are more common with $\mathrm{TH}$ than with controlled normothermia in any particular subgroup of patients. However, normothermia may be preferred in patients thought to be at particularly high risk for complications associated with hypothermia, such as severe preexisting electrolyte abnormalities, hemodynamic instability, infection, or bleeding disorders. Some of these are examples of conditions that have traditionally been considered contraindications to TH (Table 1), but may be appropriate for controlled normothermia.

\section{When should TTM be initiated?}

For the past decade since $\mathrm{TH}$ has been introduced into postarrest care, recommendations have been to start cooling patients as soon as possible after or even before ROSC. In referral centers with experience in postarrest care, the answer is relatively simple: patients should have TTM instituted as soon as they are stabilized. The question is more difficult for 
Table I Targeted temperature management: exclusion criteria and contraindications to active cooling to a $32^{\circ} \mathrm{C}-34^{\circ} \mathrm{C}$ target

\section{Exclusion criteria}

Purposeful response to verbal commands or noxious stimuli after ROSC and prior to initiation of hypothermia

Recurrent VF or refractory VT in spite of appropriate therapy

Absolute contraindications

Hemorrhagic stroke

Cardiac arrest due to trauma

GCS $>8$

Uncontrolled, active bleeding

Uncontrolled hemodynamically unstable rhythms

Relative contraindications

Prolonged cardiac arrest ( $>60$ minutes)

Refractory hypotension despite fluid and vasopressor support - consider ECMO

Thrombocytopenia (PLTs $<50 \mathrm{~K}$ ) or baseline coagulopathy

Note: Many of the contraindications mentioned in the table might not limit application of targeted temperature management, and institutional consensus should be followed on a case-by-case basis.

Abbreviations: $\mathrm{ROSC}$, return of spontaneous circulation; $\mathrm{VF}$, ventricular fibrillation; VT, ventricular tachycardia; GCS, Glasgow Coma Scale; ECMO, extracorporeal membrane oxygenation; PLTs, platelets.

physicians working in locations where postarrest patients will be routinely transferred to a referral center. Directors of prehospital services (emergency medical services) have also struggled with whether or not early initiation of TH in the field immediately after (or even prior to) ROSC would add benefit. Common sense would dictate that if TH or temperature control is beneficial, then earlier institution of it should improve its efficacy, and thus patient outcomes. However, evidence to support this has not been borne out.

There are conflicting results from comparative observation studies in humans undergoing TH. A small trial $(\mathrm{n}=49)$ in 2009 by Wolff et a ${ }^{29}$ found an independent association between shorter time to coldest temperature and cerebral performance-category score $\leq 2$ (representing a favorable outcome), although there was no association with either time to TH initiation or time to target temperature. That same year, Nielsen et $\mathrm{al}^{30}$ reported on a much larger cohort $(\mathrm{n}=986)$, and found no association between time to initiation or time to target temperature and patient outcomes. In 2011, Mooney et al reported a $20 \%$ increase in mortality for every hour's delay in TH initiation among 140 patients. $^{7}$ The ICE study group, however, found a significant independent association between early initiation of $\mathrm{TH}$ and increased mortality in their cohort of 121 Italian patients. ${ }^{31}$ Similarly, Haugk et al found improved survival (adjusted odds ratio of 1.86) among 588 patients to be independently associated with longer time to target temperature. ${ }^{32}$ While the results of these studies showed only associations and not causality, there is no con- vincing evidence that very early $\mathrm{TH}$ offers additive benefit over slightly delayed TH. It is also noteworthy that the median time to target temperature for patients randomized to $\mathrm{TH}$ in the HACA trial ${ }^{33}$ was relatively long, at 8 hours.

Perhaps more convincing data are now available from randomized trials regarding prehospital initiation of $\mathrm{TH}$. Prior to 2013, six randomized trials ${ }^{18,34-38}$ of very early prehospital initiation of TH had been performed. While patients randomized to prehospital cooling generally reached target temperature faster, none of the trials found any patientimportant benefit. Two meta-analyses ${ }^{39,40}$ of these trials published in 2013 and 2014 found no evidence of any clinically important benefit with prehospital TH. Then, Kim et al published their trial of 1,369 patients, ${ }^{8}$ nearly solidifying that prehospital TH offered no advantage over waiting to initiate TH until after hospital arrival. Kim et al's trial did show that early rearrest and pulmonary edema were more common with prehospital cooling, suggesting that rapid infusion of cold saline for immediate cooling may be associated with significant harms, though ultimately survival and neurologic recovery were similar between groups. It should be noted that approximately $50 \%$ of the patients admitted after being resuscitated from a nonshockable rhythm in Kim et al's trial did not actually receive in-hospital cooling, decreasing the certainty that the intervention would not have been useful had these patients undergone continued cooling after hospital arrival. Despite this uncertainty in patients with nonshockable rhythms, the bulk of the evidence is clearly in favor of no benefit with very early initiation of TH.

These results are perhaps not surprising in light of the evidence that now suggests that patients need not be actually cooled, as opposed to maintained at normothermic temperatures. Postarrest patients are generally below normothermic levels at hospital arrival. ${ }^{8,34,35,38}$ This means that as long as one believes that $36^{\circ} \mathrm{C}$ is an appropriate target temperature, they are already at target. Therefore, earlier initiation of "cooling" theoretically offers no benefit, as the temperature is already "controlled", until it goes outside the range that is maintained while targeting $36^{\circ} \mathrm{C}$.

Since the safety of uncontrolled temperatures above those obtained while targeting $36^{\circ} \mathrm{C}\left(36.8^{\circ} \mathrm{C}\right.$ in children $)$ is unproven, and perhaps doubtful, we suggest that TTM be mandatorily instituted before a patient becomes hyperthermic, but that as long as hyperthermia is avoided, the timing of initiation is otherwise likely to be of little relevance. This requires early institution of continuous temperature monitoring in all postarrest patients. Given that among those randomized to normothermia in Nielsen et al's 
study, the $95 \%$ interval around the average temperature was above $37.0^{\circ} \mathrm{C}$ for all time points, ${ }^{9}$ we recommend initiating aggressive temperature control measures before the (invasively measured) body temperature reaches $36.5^{\circ} \mathrm{C}$. In settings where advanced techniques are not readily or quickly available, the aggressive application of ice packs to the body with or without infusion of cold intravenous fluids prior to a temperature of $36.5^{\circ} \mathrm{C}$ should be sufficient to avoid any significant chance of hyperthermia.

\section{What methods should be employed to institute TTM?}

The landmark trials of TH in $2002,3,33$ as outlined earlier, used crude methods for cooling compared to today's technologies. The main tools employed were ice packs and cold-air cooling blankets, and it took 8 hours on average to achieve TH in the HACA trial. ${ }^{33}$ It was these methods for cooling that initially appeared so effective in improving postarrest outcomes. Since that time, methods to cool patients more efficiently have been aggressively pursued. Randomized studies have sought to define ways to cool patients faster, keep temperatures closer to target, or make temperature control easier. ${ }^{23,41}$ Some methods have proven useful for these goals, but the hopes that these more efficient methods of cooling would provide improved patient outcomes have not come to fruition.

The Arctic Sun ${ }^{\circledR}$ system is a well-studied method for external cooling that uses external cooling pads placed on various parts of the patient's body. This device mechanically circulates temperature-controlled water through dermally applied gel pads. In an often-cited study comparing Arctic Sun to cooling blankets and ice packs, patients randomized to Arctic Sun achieved target temperature more quickly (by 54 minutes on average), but good neurologic recovery was unaffected. ${ }^{23}$

Invasive means of cooling patients appear to be even more effective in terms of fast and controlled temperature control. Pittl et $\mathrm{al}^{41}$ studied the invasive CoolGuard ${ }^{\circledR}$ system against Arctic Sun in 80 postarrest patients. They found that the invasive system maintained more stable temperature control, but did not affect clinical outcomes or neuron-specific enolase levels, which the authors measured as a surrogate marker for brain damage. Bleeding complications were significantly more common in the CoolGuard group.

\section{Pearls and pitfalls in the first I 2 hours of TTM}

Patients undergoing TTM after cardiac arrest are typically critically ill, and we recommend both central venous and arterial access within the early hours of care. When cooling to $32^{\circ} \mathrm{C}-34^{\circ} \mathrm{C}$, early access can be critical, since the effects of peripheral vasoconstriction at a cooler goal temperature can make obtaining access markedly more difficult. The control of body temperature may be accomplished by many means, including the use of dermally applied gel and water-cooled pad devices, cooling blankets, cooling helmets, cooling catheters, ice packs, cooled fluid bolus, endovascular cooling devices, and ice-water lavage, though as outlined earlier it is unclear if any one method is superior to the others. ${ }^{42}$

Continuous core body temperature should be monitored to provide data to modulate cooling efforts and to avoid overcooling. Temperatures below $30^{\circ} \mathrm{C}\left(86^{\circ} \mathrm{F}\right)$ should be avoided, as adverse events, especially life threatening arrhythmia and bleeding, increase significantly below $30^{\circ} \mathrm{C} .{ }^{42}$ Esophageal, rectal, and bladder probes have been commonly used to monitor core temperature, though data suggest that rectal temperatures can be unreliable. ${ }^{43}$ Invasive lines, such as a pulmonary artery temperature probe, can be used if available, and several endovascular and gel heat-transfer cooling systems integrate a temperature probe that is used to modulate cooling system output.

\section{Sedation and shivering control}

Patient comfort and sedation should be assessed and institutional guidelines followed regarding patient monitoring and the treatment of pain and agitation. Pain can be controlled with common narcotic analgesics, such as morphine or fentanyl, and sedation can be maintained with such agents as lorazepam, midazolam, or propofol (Table 2).

Shivering, the body's attempt to maintain temperature homeostasis, can contribute to discomfort and interfere with a controlled thermic state, so prior to the induction of temperature management, pharmacological agents to control shivering should be administered. . $^{10,42,46}$ Shivering typically begins when a body temperature drops below a certain threshold, typically approximately $36^{\circ} \mathrm{C}$, and often appears regardless of the technique used to induce hypothermia. ${ }^{44,45}$ It is unclear whether different temperature targets result in significant differences in the amount of shivering, and we believe that a similar approach and algorithm for shivering control is reasonable, regardless of the temperature target chosen.

In some cases, shivering will be controlled with routine sedative drips alone (fentanyl, propofol, benzodiazepines). When these standard measures fail, the drugs most commonly employed to prevent shivering in TTM are acetaminophen, buspirone, desflurane, dexmedetomidine, and meperidine. ${ }^{46-48}$ Common sedatives used during $\mathrm{TH}$ to reduce the shivering threshold include propofol, dexmedetomidine, midazolam, and diazepam. Though fentanyl and morphine are the more commonly used opiates during TTM therapy, ${ }^{49}$ meperidine 
Table 2 Common pharmacologic and bedside adjuncts for temperature management

\begin{tabular}{|c|c|}
\hline \multicolumn{2}{|c|}{ Initiation of sedation/analgesia } \\
\hline Sedation & $\begin{array}{l}\text { Propofol (Diprivan): } 5 \mu \mathrm{g} / \mathrm{kg} \text { per minute intravenously, } \\
\text { increase by } 5-10 \mu \mathrm{g} / \mathrm{kg} / \mathrm{min} \text { increments every } 5 \text { minutes } \\
\text { until desired sedation is achieved } \\
\text { Dexmedetomidine (Precedex): I } \mu \mathrm{g} / \mathrm{kg} \text { intravenously over } \\
10 \text { minutes, followed by } 0.2-0.7 \mu \mathrm{g} / \mathrm{kg} / \mathrm{h} \text { continuously } \\
\text { Midazolam (Versed): } 0.02-0.1 \mathrm{mg} / \mathrm{kg} / \mathrm{h} \text { (I-7 mg/h) } \\
\text { intravenous infusion } \\
\text { Lorazepam (Ativan): } 0.01-0.1 \mathrm{mg} / \mathrm{kg} / \mathrm{h} \text { intravenous } \\
\text { infusion to maintain desired level of sedation }\end{array}$ \\
\hline Analgesia & $\begin{array}{l}\text { Fentanyl (Sublimaze): } 0.7-10 \mu \mathrm{g} / \mathrm{kg} / \mathrm{h} \text { intravenous } \\
\text { infusion }\end{array}$ \\
\hline \multicolumn{2}{|c|}{ Initiation of shiver control } \\
\hline First line & $\begin{array}{l}\text { Acetaminophen (Tylenol): } 650-1,000 \mathrm{mg} \text { orally/rectally } \\
\text { every } 4-6 \text { hours } \\
\text { Buspirone (Buspar): } 30 \mathrm{mg} \text { orally every } 8 \text { hours } \\
\text { Meperidine (Demerol): } 25-50 \mathrm{mg} \text { intravenously every } \\
4 \text { hours as needed } \\
\text { Application of arm/skin counterwarming via forced-air } \\
\text { warming unit, hand mitts }\end{array}$ \\
\hline Second line & $\begin{array}{l}\text { Magnesium sulfate: } 2-5 \mathrm{~g} \text { infused over } 5 \text { hours } \\
\text { Dexmedetomidine (Precedex): } 0.2-0.7 \mu g / \mathrm{kg} / \mathrm{h} \\
\text { intravenously for mild sedation }\end{array}$ \\
\hline Third line & $\begin{array}{l}\text { Propofol (Diprivan): } 50-75 \mu \mathrm{g} / \mathrm{kg} / \mathrm{min} \text { intravenously to } \\
\text { deep sedation } \\
\text { Vecuronium (Norcuron): } 0.1 \mathrm{mg} / \mathrm{kg} \text { intravenous bolus } \\
\text { as needed; can be followed by intravenous infusion } \\
\text { I } \mu \mathrm{g} / \mathrm{kg} / \mathrm{min} \text { infusion for maintenance } \\
\text { Goal: bispectral index value } 40-60 \text { or one muscle } \\
\text { twitch out of four in train of four monitoring } \\
\text { Rocuronium (Zemuron): } 0.6-1.2 \mathrm{mg} / \mathrm{kg} \text { intravenous bolus } \\
\text { as needed, can be followed by a } 0.0 \mathrm{I}-0.012 \mathrm{mg} / \mathrm{kg} / \mathrm{min} \\
\text { infusion for maintenance } \\
\text { Goal: bispectral index value } 40-60 \text { or one muscle twitch } \\
\text { out of four in train of four monitoring } \\
\text { Cisatracurium (Nimbex): } 0.03 \mathrm{mg} / \mathrm{kg} \text { intravenous bolus } \\
\text { as needed; can be followed by a I-2 } \mu \mathrm{gg} / \mathrm{kg} / \mathrm{min} \text { infusion } \\
\text { for maintenance } \\
\text { Goal: bispectral index value } 40-60 \text { or one muscle } \\
\text { twitch out of four in train of four monitoring }\end{array}$ \\
\hline Initiation & asopressors \\
\hline & $\begin{array}{l}\text { Norepinephrine (Levophed): begin at } 0.01 \mu \mathrm{g} / \mathrm{kg} / \mathrm{min} \\
\text { intravenously, titrate to MAP goal } \\
\text { Epinephrine: begin at } 2 \mu \mathrm{g} / \mathrm{min} \text { intravenously (in adults), } \\
\text { titrate to MAP goal }\end{array}$ \\
\hline
\end{tabular}

Abbreviation: MAP, mean arterial pressure.

has been the most efficacious of the opiates with regard to shiver management, with recorded reductions in the shivering threshold of $1.2^{\circ} \mathrm{C}-6.1^{\circ} \mathrm{C}$ to a level $33^{\circ} \mathrm{C} .{ }^{47,49-52}$ Buspirone, a serotonin $1 \mathrm{~A}$ partial agonist, and meperidine appear to lower the shivering threshold in synergism, achieving even lower shivering thresholds. ${ }^{53}$ Magnesium sulfate has been studied as a bolus with infusion as a means to improve targeted cooling times ${ }^{54}$ and perhaps enhance shivering thresholds in combination with other agents. ${ }^{48,55}$
Nonpharmacologic means of shiver reduction largely focus on skin counterwarming (total-body forced-air rewarming, focal hand rewarming, and focal face/head rewarming) as a means to reduce shivering and vasoconstrictive thresholds. ${ }^{48,56,57}$ Evidence supports a $1{ }^{\circ} \mathrm{C}$ decrease in shivering threshold for every $4^{\circ} \mathrm{C}$ increase in skin temperature. ${ }^{56}$ Endovascular cooling may allow better access to the skin to employ counterwarming compared to external cooling measures that require the skin to be cooled directly. When shivering occurs despite optimal pharmacologic and nonpharmacologic means, protocols often include the use of a paralytic agent (ie, neuromuscular blocker) to control shivering. Because of the challenges of monitoring sedation, neurological examination, and seizures when paralytic agents are used, many protocols call for the discontinuation of paralytics once the core body-temperature target is achieved. The protocol may then allow for paralytic resumption if shivering is observed.

\section{Monitoring and supportive therapy}

Postarrest patients should be placed on a continuous cardiac monitor with monitoring of routine vital signs and oxygen saturation. The most commonly encountered arrhythmia associated with TH is bradycardia, and a heart rate less than 40 can be seen frequently, but is rarely a cause for concern in the absence of blood-pressure instability. In the event of life-threatening dysrhythmia, hemodynamic instability, or bleeding, active cooling should be discontinued and the patient rewarmed to a higher target. ${ }^{10} \mathrm{~A}$ mean arterial pressure (MAP) goal of more than $80 \mathrm{mmHg}$ is preferred by some because it should theoretically support cerebral perfusion, as hypertension in the postresuscitative phase is potentially neuroprotective. ${ }^{21}$ Norepinephrine, beginning at $0.01 \mu \mathrm{g} / \mathrm{kg} / \mathrm{min}$, can be titrated to whatever MAP goal is thought to be best in the individual patient, though practitioners should balance MAP goals and the goal of higher cerebral perfusion with the potential complications of increasing cardiac demands..$^{21,42}$

In addition to the standard neuroprotective strategies, such as placing the head of the bed at $30^{\circ}$, lung-protective ventilation strategies, standard bedside line and catheter care, and pneumonia-prevention protocols should be followed. Skin condition should be checked as frequently as every 2-6 hours for potential thermal injury, which can be caused by thermal blankets or pads, and for breakdown as a consequence of vasoconstriction. Core temperature should be monitored hourly and regularly confirmed with a secondary temperature-monitoring device when actively cooling. Ventilation should be set to maintain $\mathrm{CO}_{2}$ partial pressure within the reference range $(35-45 \mathrm{mmHg})$ and 
arterial blood gases followed every 6 hours, as metabolic end points change with temperature.

Patient hematologic testing, including a complete blood count, a basic metabolic panel, troponin level, arterial blood gas level, prothrombin time, and partial thromboplastin time, should be collected at temperature-management initiation ( 0 hour) and collected every 6-12 hours during cooling or as per institutional protocols. An elevated serum glucose level is potentially deleterious to the injured brain, and glycemic control should be maintained via institutional protocol. Hypokalemia, which may be exacerbated by insulin administration, commonly occurs as a result of intracellular shift during hypothermia. Conversely, potassium exits the cells when patients are rewarmed, and hyperkalemia may occur, especially if potassium is replaced during the rewarming phase. Potassium values less than $3.5 \mathrm{mEq} / \mathrm{L}$ should be corrected during induction and cooling, but potassium administration should be stopped at the final 2 hours of cooling and once rewarming begins. ${ }^{42,58}$

\section{Conclusion}

TTM remains an integral part of post-cardiac arrest care. Current evidence supports either TH at $32^{\circ} \mathrm{C}-34^{\circ} \mathrm{C}$ or controlled normothermia at $36^{\circ} \mathrm{C}$, though individual patient characteristics may lead the clinician to favor one target over the other in certain cases. In a postarrest patient, continuous temperature monitoring should be initiated as soon as possible, and TTM should be started prior to any temperature greater than $36.5^{\circ} \mathrm{C}$. No clinical benefit has been shown with any particular method of TTM over another, although direct normothermia-versus-hypothermia comparisons have been limited to advanced techniques. Patients undergoing TTM should have continuous cardiac monitoring and have electrolyte checks frequently, as abnormalities are common in this group of patients. Patients should be sedated, and in many cases will require further methods, as discussed, to control shivering.

\section{Disclosure}

The authors report no conflicts of interest in this work.

\section{References}

1. Mozaffarian D, Benjamin EJ, Go AS, et al. Heart disease and stroke statistics - 2015 update: a report from the American Heart Association. Circulation. 2015;131(4):e29-e322.

2. Sasson C, Rogers MA, Dahl J, Kellermann AL. Predictors of survival from out-of-hospital cardiac arrest: a systematic review and metaanalysis. Circ Cardiovasc Qual Outcomes. 2010;3(1):63-81.

3. Bernard SA, Gray TW, Buist MD, et al. Treatment of comatose survivors of out-of-hospital cardiac arrest with induced hypothermia. NEngl J Med. 2002;346(8):557-563.
4. Hypothermia after Cardiac Arrest study group. Mild therapeutic hypothermia to improve the neurologic outcome after cardiac arrest. N Engl J Med. 2002;346(8):549-556.

5. Busch M, Soreide E, Lossius HM, Lexow K, Dickstein K. Rapid implementation of therapeutic hypothermia in comatose out-of-hospital cardiac arrest survivors. Acta Anaesthesiol Scand. 2006;50(10): $1277-1283$.

6. Hachimi-Idrissi S, Corne L, Ebinger G, Michotte Y, Huyghens L. Mild hypothermia induced by a helmet device: a clinical feasibility study. Resuscitation. 2001;51(3):275-281.

7. Mooney MR, Unger BT, Boland LL, et al. Therapeutic hypothermia after out-of-hospital cardiac arrest: evaluation of a regional system to increase access to cooling. Circulation. 2011;124(2):206-214.

8. Kim F, Nichol G, Maynard C, et al. Effect of prehospital induction of mild hypothermia on survival and neurological status among adults with cardiac arrest: a randomized clinical trial. JAMA. 2014;311(1):45-52.

9. Nielsen N, Wetterslev J, Cronberg T, et al. Targeted temperature management at $33^{\circ} \mathrm{C}$ versus $36^{\circ} \mathrm{C}$ after cardiac arrest. $N$ Engl J Med. 2013;369(23):2197-2206.

10. Polderman K, Nielsen N, Graffagnino C, Wayne M. Therapeutic hypothermia in post-cardiac arrest. Ther Hypothermia Temp Manag. 2014; 4(4):154-158.

11. Polderman KH. Mechanisms of action, physiological effects, and complications of hypothermia. Crit Care Med. 2009;37(7 Suppl): S186-S202.

12. Polderman KH. Application of therapeutic hypothermia in the ICU: opportunities and pitfalls of a promising treatment modality. Part 1: Indications and evidence. Intensive Care Med. 2004;30(4):556-575.

13. Polderman KH. Induced hypothermia and fever control for prevention and treatment of neurological injuries. Lancet. 2008;371(9628): 1955-1969.

14. Sendelbach S, Hearst MO, Johnson PJ, Unger BT, Mooney MR. Effects of variation in temperature management on cerebral performance category scores in patients who received therapeutic hypothermia post cardiac arrest. Resuscitation. 2012;83(7):829-834.

15. Sinclair HL, Andrews PJ. Bench-to-bedside review: hypothermia in traumatic brain injury. Crit Care. 2010;14(1):204.

16. Taccone FS, Donadello K, Beumier M, Scolletta S. When, where and how to initiate hypothermia after adult cardiac arrest. Minerva Anestesiol. 2011;77(9):927-933.

17. Calver P, Braungardt T, Kupchik N, Jensen A, Cutler C. The big chill: improving the odds after cardiac arrest. $R N .2005 ; 68(5): 58-62$; quiz 63.

18. Callaway CW, Schmicker RH, Brown SP, et al. Early coronary angiography and induced hypothermia are associated with survival and functional recovery after out-of-hospital cardiac arrest. Resuscitation. 2014;85(5):657-663.

19. Hörburger D, Testori C, Sterz F, et al. Mild therapeutic hypothermia improves outcomes compared with normothermia in cardiac-arrest patients - a retrospective chart review. Crit Care Med. 2012;40(8): 2315-2319.

20. Heart and Stroke Foundation of Canada. Therapeutic hypothermia after cardiac arrest. ILCOR advisory statement, October 2002. CJEM. 2005;7(2):129.

21. Bro-Jeppesen J, Annborn M, Hassager C, et al. Hemodynamics and vasopressor support during targeted temperature management at $33^{\circ} \mathrm{C}$ versus $36^{\circ} \mathrm{C}$ after out-of-hospital cardiac arrest: a post hoc study of the target temperature management trial. Crit Care Med. 2015;43(2): 318-327.

22. Moler FW, Silverstein FS, Holubkov R, et al. Therapeutic hypothermia after out-of-hospital cardiac arrest in children. $N$ Engl J Med. 2015;372(20):1898-1908.

23. Heard KJ, Peberdy MA, Sayre MR, et al. A randomized controlled trial comparing the Arctic Sun to standard cooling for induction of hypothermia after cardiac arrest. Resuscitation. 2010;81(1):9-14.

24. Mongardon N, Perbet S, Lemiale V, et al. Infectious complications in out-of-hospital cardiac arrest patients in the therapeutic hypothermia era. Crit Care Med. 2011;39(6):1359-1364. 
25. Seder DB, Riker RR. Complications of therapeutic hypothermia after cardiac arrest: does the type of cooling device matter? Crit Care Med. 2011;39(3):582-583.

26. Stockmann H, Krannich A, Schroeder T, Storm C. Therapeutic temperature management after cardiac arrest and the risk of bleeding: systematic review and meta-analysis. Resuscitation. 2014;85(11):1494-1503.

27. Noyes AM, Lundbye JB. Managing the complications of mild therapeutic hypothermia in the cardiac arrest patient. J Intensive Care Med. 2015;30(5):259-269.

28. Soleimanpour H, Rahmani F, Golzari SE, Safari S. Main complications of mild induced hypothermia after cardiac arrest: a review article. J Cardiovasc Thorac Res. 2014;6(1):1-8.

29. Wolff B, Machill K, Schumacher D, Schulzki I, Werner D. Early achievement of mild therapeutic hypothermia and the neurologic outcome after cardiac arrest. Int J Cardiol. 2009;133(2):223-228.

30. Nielsen N, Hovdenes J, Nilsson F, et al. Outcome, timing and adverse events in therapeutic hypothermia after out-of-hospital cardiac arrest. Acta Anaesthesiol Scand. 2009;53(7):926-934.

31. Italian Cooling Experience (ICE) study group. Early- versus lateinitiation of therapeutic hypothermia after cardiac arrest: preliminary observations from the experience of 17 Italian intensive care units. Resuscitation. 2012;83(7):823-828.

32. Haugk M, Testori C, Sterz F, et al. Relationship between time to target temperature and outcome in patients treated with therapeutic hypothermia after cardiac arrest. Crit Care. 2011;15(2):R101.

33. Hypothermia after Cardiac Arrest study group. Mild therapeutic hypothermia to improve the neurologic outcome after cardiac arrest. $N E n g l$ J Med. 2002;346(8):549-556.

34. Bernard SA, Smith K, Cameron P, et al. Induction of therapeutic hypothermia by paramedics after resuscitation from out-of-hospital ventricular fibrillation cardiac arrest: a randomized controlled trial. Circulation. 2010;122(7):737-742.

35. Bernard SA, Smith K, Cameron P, et al. Induction of prehospital therapeutic hypothermia after resuscitation from nonventricular fibrillation cardiac arrest. Crit Care Med. 2012;40(3):747-753.

36. Castrén M, Nordberg P, Svensson L, et al. Intra-arrest transnasal evaporative cooling: a randomized, prehospital, multicenter study (PRINCE: Pre-ROSC IntraNasal Cooling Effectiveness). Circulation. 2010;122(7):729-736.

37. Kamarainen A, Virkkunen I, Tenhunen J, Yli-Hankala A, Silfvast T. Prehospital therapeutic hypothermia for comatose survivors of cardiac arrest: a randomized controlled trial. Acta Anaesthesiol Scand. 2009;53(7):900-907.

38. Kim F, Olsufka M, Longstreth WT Jr, et al. Pilot randomized clinical trial of prehospital induction of mild hypothermia in out-of-hospital cardiac arrest patients with a rapid infusion of $4^{\circ} \mathrm{C}$ normal saline. Circulation. 2007;115(24):3064-3070.

39. Hunter BR, O’Donnell DP, Allgood KL, Seupaul RA. No benefit to prehospital initiation of therapeutic hypothermia in out-of-hosptial cardiac arrest: a systematic review and meta-analysis. Acad Emerg Med. 2014;21(4):355-364.

40. Diao M, Huang F, Guan J, et al. Prehospital therapeutic hypothermia after cardiac arrest: a systematic review and meta-analysis of randomized controlled trials. Resuscitation. 2013;84(8):1021-1028.
41. Pittl U, Schratter A, Desch S, et al. Invasive versus non-invasive cooling after in- and out-of-hospital cardiac arrest: a randomized trial. Clin Res Cardiol. 2013;102(8):607-614.

42. Polderman KH, Herold I. Therapeutic hypothermia and controlled normothermia in the intensive care unit: practical considerations, side effects, and cooling methods. Crit Care Med. 2009;37(3):1101-1120.

43. Weingart S, Mayer S, Polderman K. Rectal probe temperature lag during rapid saline induction of hypothermia after resuscitation from cardiac arrest. Resuscitation. 2009;80(7):837-838.

44. Sessler DI. Perioperative thermoregulation and heat balance. Ann NY Acad Sci. 1997;813:757-777.

45. Sessler DI. Perioperative heat balance. Anesthesiology. 2000;92(2): 578-596.

46. Seder DB, May T, Fraser GL, Riker RR. Shivering during therapeutic hypothermia after cardiac arrest. Resuscitation. 2011;82(2):149.

47. Weant KA, Martin JE, Humphries RL, Cook AM. Pharmacologic options for reducing the shivering response to therapeutic hypothermia. Pharmacotherapy. 2010;30(8):830-841.

48. Logan A, Sangkachand P, Funk M. Optimal management of shivering during therapeutic hypothermia after cardiac arrest. Crit Care Nurse. 2011;31(6):e18-e30.

49. Chamorro C, Borrallo JM, Romera MA, Silva JA, Balandin B. Anesthesia and analgesia protocol during therapeutic hypothermia after cardiac arrest: a systematic review. Anesth Analg. 2010;110(5):1328-1335.

50. Kurz A, Ikeda T, Sessler DI, et al. Meperidine decreases the shivering threshold twice as much as the vasoconstriction threshold. Anesthesiology. 1997;86(5):1046-1054.

51. Ikeda T, Kurz A, Sessler DI, et al. The effect of opioids on thermoregulatory responses in humans and the special antishivering action of meperidine. Ann N Y Acad Sci. 1997;813:792-798.

52. Kimberger O, Ali SZ, Markstaller M, et al. Meperidine and skin surface warming additively reduce the shivering threshold: a volunteer study. Crit Care. 2007;11(1):R29.

53. Mokhtarani M, Mahgoub AN, Morioka N, et al. Buspirone and meperidine synergistically reduce the shivering threshold. Anesth Analg. 2001;93(5):1233-1239.

54. Zweifler RM, Voorhees ME, Mahmood MA, Parnell M. Magnesium sulfate increases the rate of hypothermia via surface cooling and improves comfort. Stroke. 2004;35(10):2331-2334.

55. Wadhwa A, Sengupta P, Durrani J, et al. Magnesium sulphate only slightly reduces the shivering threshold in humans. Br J Anaesth. 2005;94(6):756-762.

56. Cheng C, Matsukawa T, Sessler DI, et al. Increasing mean skin temperature linearly reduces the core-temperature thresholds for vasoconstriction and shivering in humans. Anesthesiology. 1995;82(5):1160-1168.

57. Badjatia N, Strongilis E, Prescutti M, et al. Metabolic benefits of surface counter warming during therapeutic temperature modulation. Crit Care Med. 2009;37(6):1893-1897.

58. Polderman KH. Application of therapeutic hypothermia in the intensive care unit. Opportunities and pitfalls of a promising treatment modality - part 2: practical aspects and side effects. Intensive Care Med. 2004;30(5):757-769.

Open Access Emergency Medicine

\section{Publish your work in this journal}

Open Access Emergency Medicine is an international, peer-reviewed, open access journal publishing original research, reports, editorials, reviews and commentaries on all aspects of emergency medicine. The manuscript management system is completely online and includes a very quick and fair peer-review system, which is all easy to use.

\section{Dovepress}

Visit http://www.dovepress.com/testimonials.php to read real quotes from published authors. 